\title{
INFRARED THERMAL IMAGING AS A NON-DESTRUCTIVE INVESTIGATION METHOD FOR BUILDING ARCHAEOLOGICAL PURPOSES
}

\author{
A. Luib ${ }^{1}$ \\ ${ }^{1}$ KDWT, Centre for Heritage Conservation Studies and Technologies, University of Bamberg, Germany \\ anna.luib@uni-bamberg.de
}

Commission II, WG II/8

KEY WORDS: Infrared Thermography, IR thermal imaging, Building Archaeology, Heritage Conservation, NDT Monitoring

\begin{abstract}
:
The presented research approach evaluates the applicability of IRT as a non-destructive testing method for Building Archaeological scientific purposes. Within a qualitative thermographic analysis, focusing on the examination of thermal patterns and anomalies, the evidence of Building Archaeological phenomena is demonstrated. Several radiometric assessments display how hitherto unknown subsurface structures and constructive interrelations are detected and simultaneously evaluated in order to both describe the historic fabric's quality and integrate them into the comprehensive Building Archaeological stratigraphic analysis. With IRT providing a standardised mapping of material features, structural configurations and thermal anomalies, the procedure presented enables more detailed estimations of both condition and constructive contiguity of historic fabric in a comprehensive assessment.
\end{abstract}

\section{INTRODUCTION}

\subsection{Context}

Infrared Thermography in Heritage Conservation has evolved significantly over the past few years. The technical devices for assessing and documenting thermal infrared phenomena have both improved and diversified. Their range of implementation for scientific purposes has already produced a variety of promising, interdisciplinary research approaches (Rosina et al., 2019), (Sfarra et al., 2019). In the field of cultural heritage and preservation sciences, IR-technology has been widely applied as a new approach to exploring murals, frescoes, panel paintings and cracks in detail, and for damage evaluation e.g (Bodnar et al., 2012), (Casapulla et al., 2018), (Kordatos et al., 2013). Another of its fast-growing fields of application is in conducting energetic surveys of the built environment, especially building envelopes and their thermal behaviour. This substantially affects cultural heritage objects and their thermal performance and efficiency, which is usually declared deficient. In addition, various combinations of Infrared Thermography with technologies such as 3D scanning and Structure from Motion (SfM) and the mapping of IRT-data on point clouds, enlarging the range of multispectral analysis, have been examined (Maierhofer et al., 2010), (Moropolou et al., 2018), (Yastikli et al., 2013). IRT research has thus produced a broad variety of very specific implementations of thermal imaging, in the technical sector particularly regarding feasibility and implementation standards (Kandemir-Yucel et al., 2007), (Lerma et al., 2018).

\subsection{Objective}

Compared to the technical developments, comprehensive scientific IRT approaches to large-scale cultural heritage buildings, fabric and structures remain rare. A lot of IRT research revolves around the testing of IRT's technical potential, feasibility and repeatability of experimental procedures. Although their execution can be implemented on cultural heritage objects, the respective object is mostly exchangeable under consistent technical and methodological research questions. The research presented here, however, treats the individual cultural heritage object as the main source of Building Archaeological research. In this convergence, IRT remains a versatile examination device for Building Archaeology. However, regarding the historic fabric as the focus of the research, requires adapting existing IRT methodological strategies, for example, IRT measuring settings must be adjusted for each individual object. Holistic research approaches in Building Archaeological contexts comprise integrated examinations of large structures, encompassing buildings, single heritage objects, historic constructions and individual building materials at different scales.

The results presented here will therefore provide an overview of the current implementation of IRT in the field of heritage conservation, and especially in building structures. It will describe the results of IRT as a stand-alone technique by exploiting its methodological research potential adjusted to individual objects. The main aim of the campaign was to assess and evaluate the applicability of IRT as a non-destructive testing method for Building Archaeological scientific purposes. As Building Archaeology always contextualises the individual object, IRT is consequently tested as a contiguity-generating device. Coherency of structures, cohesive material features, interdependencies between them and correlations of constructions provide essential information on historic materials. With regard to the surrounding conditions, the presented IRT application proves a promising tool for visualizing them.

While IRT and photogrammetry methodologies are widely applied, this approach focuses on the qualitative description of IRT as both an objective documentation method and a method for generating measurements which can be used in comparisons. IRT not only detects temperature variations in building fabric, their defects, damages and material losses, but it is at the same time a profound method for visualising further specific properties of cultural heritage objects.

Consequently, the research question comprises two aspects: How - and to what extent - can IRT be applied scientifically in preliminary examinations of cultural heritage objects? And which categories of findings that are important for an initial estimation of a heritage object's general condition can be provided by IRT? 


\section{METHODS AND PROCEDURE}

\subsection{Case Study}

On these grounds, a sample of historic masonry constructions were examined with a portable infrared camera used as a standalone radiometric measuring unit. The radiometric examinations comprise measurements on vertical and horizontal building structures. Consisting of both interior and exterior walls and vaulted structures in heated and unheated areas, the case study displays a variety of masonry techniques from different ages and phases, i.e., the use of different mortars, as well as natural stones and bricks. All of them were plastered irregularly with varying thicknesses and using different plasters; additionally, some were coated or painted.

\subsection{Data Acquisition}

The testing in all cases was conducted in-situ, all of the historic constructions being part of buildings still in use.

The infrared camera-system used is a LWIR- VarioCam (InfraTec) with a 30mm lens, a spectral range of 7.5-14 $\mu \mathrm{m}$ and an uncooled microbolometer Focal Plane Array detector. Detector format is $640 \times 480 \mathrm{IR}$ pixels, image format with optomechanical MicroScan 1,280 $\times 960$ IR pixels through dynamic resolution enhancement. The measurable temperatures range from $-40 \ldots 2,000{ }^{\circ} \mathrm{C}$ with accuracy of $\pm 1{ }^{\circ} \mathrm{C}$ or $\pm 1 \%$. Temperature resolution is up to $0.02 \mathrm{~K}$ at $30{ }^{\circ} \mathrm{C}$. Frame rate is $60 \mathrm{~Hz}$ for full-frame recording.

An integrated laser range finder measures the distance from the focussed object to the camera position, and the integrated digital camera produces simultaneous visual photographs for each IR measurement. The approach used is passive thermography. No artificial excitation sources (e.g. heating, lighting) were applied. However, this research takes into consideration natural excitation through sunlight and shading effects. The sample objects were tested several times under varying environmental conditions and from different angles, generating an objectification of the measured results through the comparison of multiple measurements. Employing a Focal Plane Array (FPA), the camera's infrared imaging detector operates on very short integration times and is thus not affected by fast changing surrounding conditions.

Besides the repetitive thermal imaging process, the adjusting of temperature scale, measuring distance and focus, the examination procedure also comprises a standardized documentation of these varying environmental conditions e.g. exterior temperature and camera temperature, humidity, date and time, integration time, horizontal and vertical field of view (HFOV and VFOV) and calibration settings. This allows the recordings to be repeated exactly in comparative studies or future campaigns and qualifies the thermal examination approach as a promising method for monitoring. As most of the historic building materials have a rather high emissivity (usually above 0.8), the emission coefficient setting was fixed at 1.0. No additional determination of emissivity values was carried out. The survey presented here was conducted as a qualitative thermographic analysis, focusing on the examination of thermal patterns and anomalies. The comparison is not of absolute radiometric values or quantified temperature measurements - as found in quantitative IRT - but instead overall thermal patterns, constitute the core recording. Qualitative IRT provides perfect evidence of Building Archaeological phenomena by depicting relative temperature relations, junctions, discontinuities and disruptions.

\subsection{Post-Processing}

Each of the in-situ measurements was performed in around 3-4 hours of accumulated site time and 5-6 h off-site post-processing. The Post-Processing of the recorded radiometric data is mainly conducted with the control- and evaluation software IRBIS ${ }^{\circledR} 3$. As Building Archaeology focuses on the qualitative aspects of IRT, post-processing concentrates on analysing constructive features, displaying the building components spectral information and visualising correlations and anomalies in historic fabric.

Data evaluation therefore always comprises the visual image of the radiometric data combined with a relating temperature scale, temperature profiles, histogram, parameter setting list, column value chart and profile chart. (Fig. 1)

The resulting thermograms display the temperature values in duplicate: False colour images for better differentiating spectral

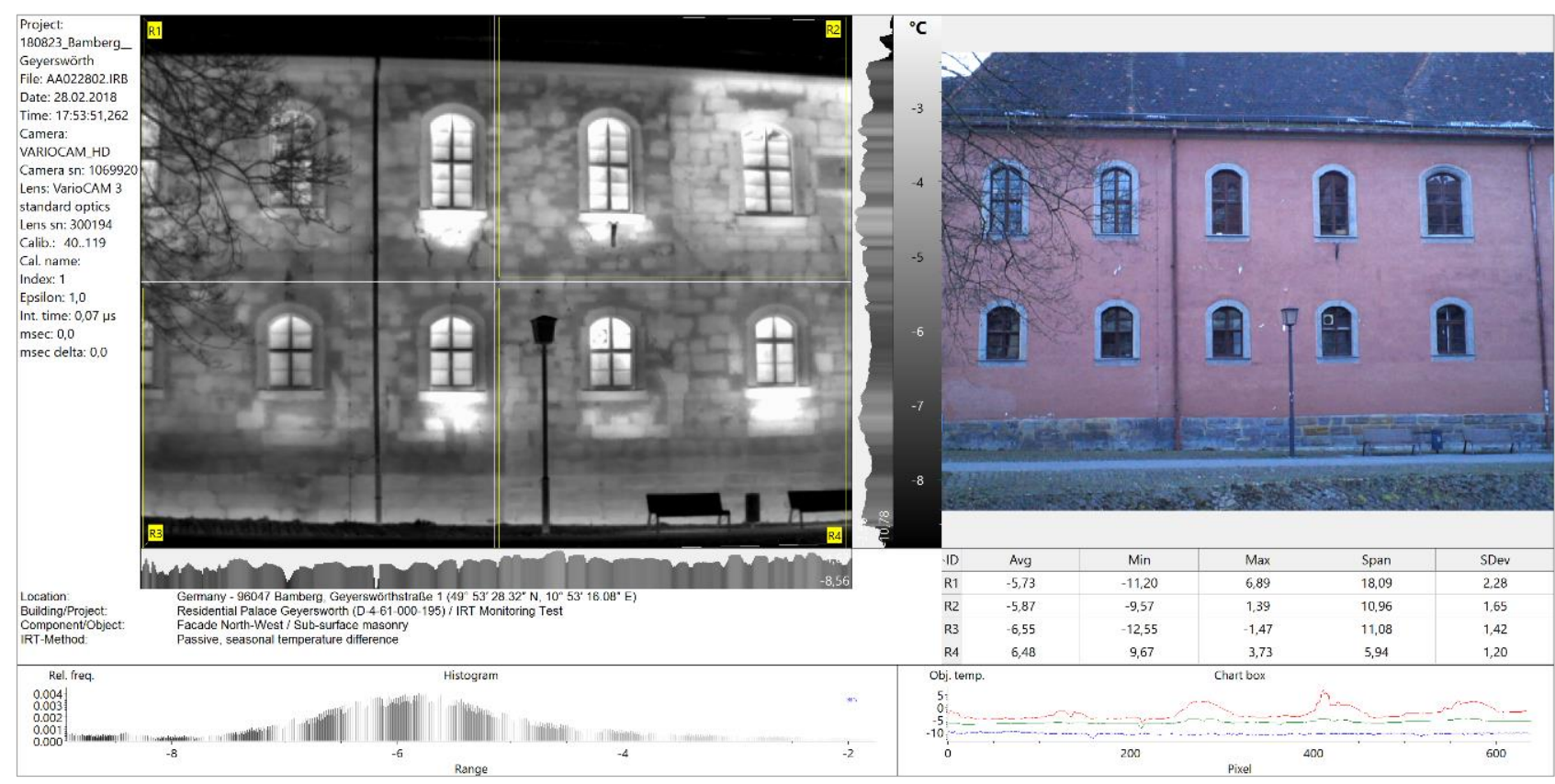

Figure 1: Greyscale visualisation of radiometric information, depicting thermal distribution, variations and anomalies in temperature values. 
distribution and greyscale images for higher contrasts of thermal features. Post-processing them involves adjusting level and span of thermal visualisations. The related histogram quantitatively visualises the measured radiometric values, the column value chart displays the minimum, maximum and average values for each column (x-profile) of a thermal image. For comparative purposes, the visualisation always comprises a complementary combination of both the thermal infrared image and the relating visual image of the measuring situation. This does not only locate the thermogram's extent and position of capturing, but also provides a framework for mapping the thermal infrared data onto a metric scheme. As a hybrid photogrammetric product, this socalled merging of visual and infrared data can elucidate the benefit of multispectral imaging techniques in the infrared range.

\section{FINDINGS}

\subsection{Vertical Masonry Structures}

The radiometric survey of vertical masonry structures was conducted at the Residential Palace Geyerswörth in Bamberg. All four façade sides were examined repeatedly, in different months and under varying temperature and solar conditions. Being plastered and coated in a continuous texture with thicknesses from 3-5 centimetres, all four sides present comparable readings. Measuring distances vary between 15-35 metres, depending on the accessibility of the façades. Additional detail documentation ranged from 2-5 metres.

The thermogram (Fig.1) depicts a section of the northeast façade, displaying sub-surface structures with varying joint network, alterations of building structures and stone replacements. The post processing illustrates these façade parts' radiometric data in three versions: V1 (Fig.1: Greyscale visualisation of temperature values) depicts optimal imaging contrasts, hence improving the visibility of distinctive differences in materiality. V2 (Fig.2: Greyscale + red marker visualisation) marks thermal inhomogeneity, outlining regions with the highest temperature values. V3 (Fig.3: Merging of thermal and visual image) locates the extent and position of the radiometric data and provides a framework for mapping thermal infrared information onto visual images. For deducing Building Archaeological findings, Version 1 illustrates the most distinct thermal features and therefore the most precisely detailed information. Greyscale-imaging with a colour count of 1000 values and a moderate linearity yielded the best contrasts, far better than the common all-colour version.

As the thermal properties of masonries correlate to both their stone's and mortar's internal structure and external structural

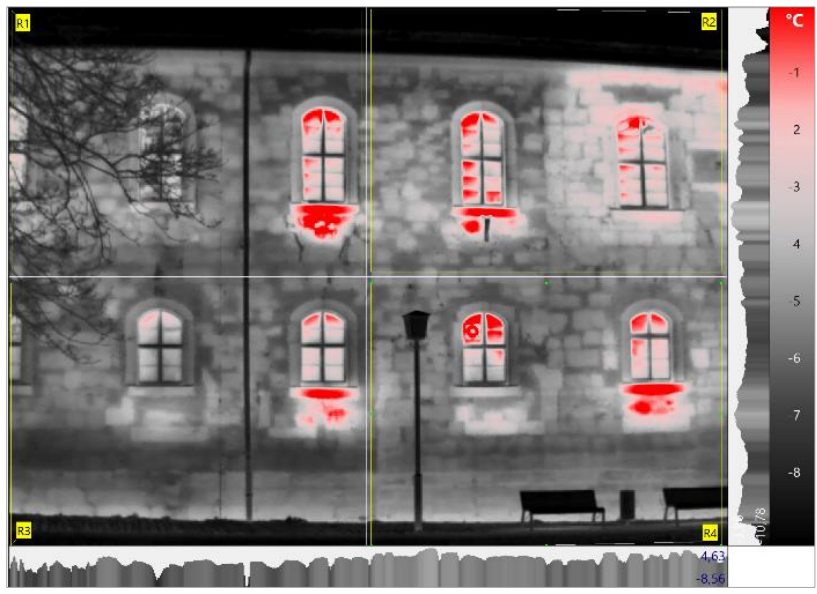

Figure 2: Greyscale and red marker visualisation. Focus on regions with highest temperature values. cohesion, they entail varying heat fluxes. Interruptions or heterogeneities in these heat fluxes are detectable with IRT cameras, hinting at structural junctions, sections or material related anomalies. Therefore, regions of radiometric irregularities are suggestive of findings relevant for Building Archaeological investigations.

In the case of the plastered masonry façades, IRT efficiently reveals stone sizes, masonry bond and joint pattern. The masonry in this example comprises various stone sizes, all of them belonging to approximately medium-sized historic formats. Because of the inconsistent joint runs and their varying sizes, a continuous masonry bond is not evident at first sight. (Fig. 1) Of course, smaller areas form coherent bonds, but they are often disrupted by alterations not fitting into their pattern. An example would be the window on the upper right side in region $\mathrm{R} 2$ of the thermogram. The masonry around this region produces a distinct thermal imprint on the façade that is vertically limited by a straight line running down in the middle between the two windows. The masonry bonds around the left window of R2 appear thermally more inert. (Fig.2) This could be due to an alteration in stone fabric to a more inert stone material, or a change in interior room temperature conditions resulting in a stronger heat flux. Monitoring this region over the course of a year revealed a consistent phenomenon even in the summer climate, when there is minimum heat transition. The reason for this thermal anomaly must therefore lie in material-related factors. An alteration of material properties in turn hints at a structural junction in the façade's masonry construction. This radiometric record can therefore help decipher the chronology of building junctions. Respective junctions can also be assigned to not only the stone material, but also variations in their sizes, joint run irregularities and alterations of mortar material. Thermal images prove very useful for the assessment of these phenomena. (Fig.3) In addition, they also clearly display several subsequently altered structures on the façade. All the first-floor windows have apparently been altered in both size and position. Below the current window sills, the thermal image outlines the former sills lying deeper and thus belonging to larger window openings. Their size corresponds to the size of the windows on the second floor, suggesting that they must have originally shared the same dimensions and were later reduced. This record is supported by the fact, that the fillings of the lower window parts display different thermal properties compared to the surrounding stone fabric. Deducing Building Archaeological findings from thermal examinations and implementing them into a stratigraphy is also valid for regions of repair works.

Repairing often implies the exchange or alteration of fabric, which are in turn indicated by varying thermal performance.

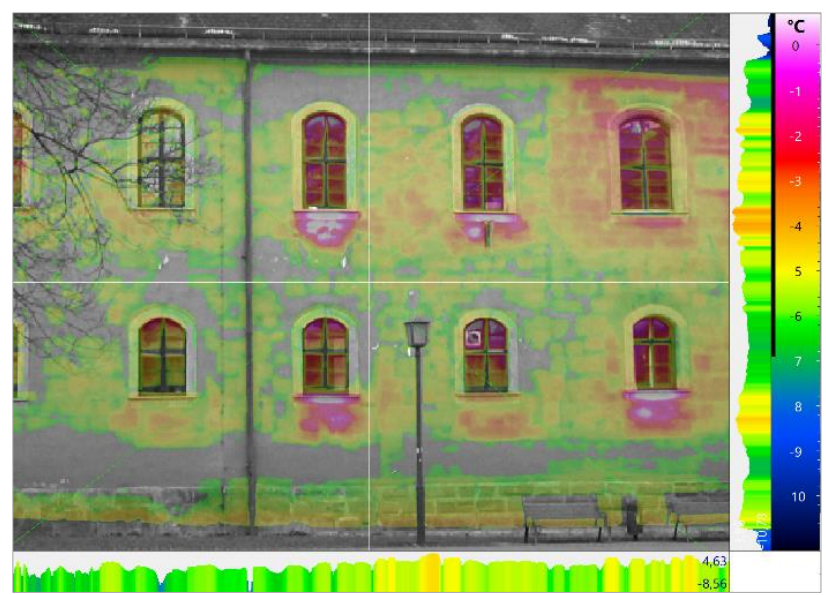

Figure 3: Merging of thermal and visual image. Location of the extent and position of the radiometric data. 


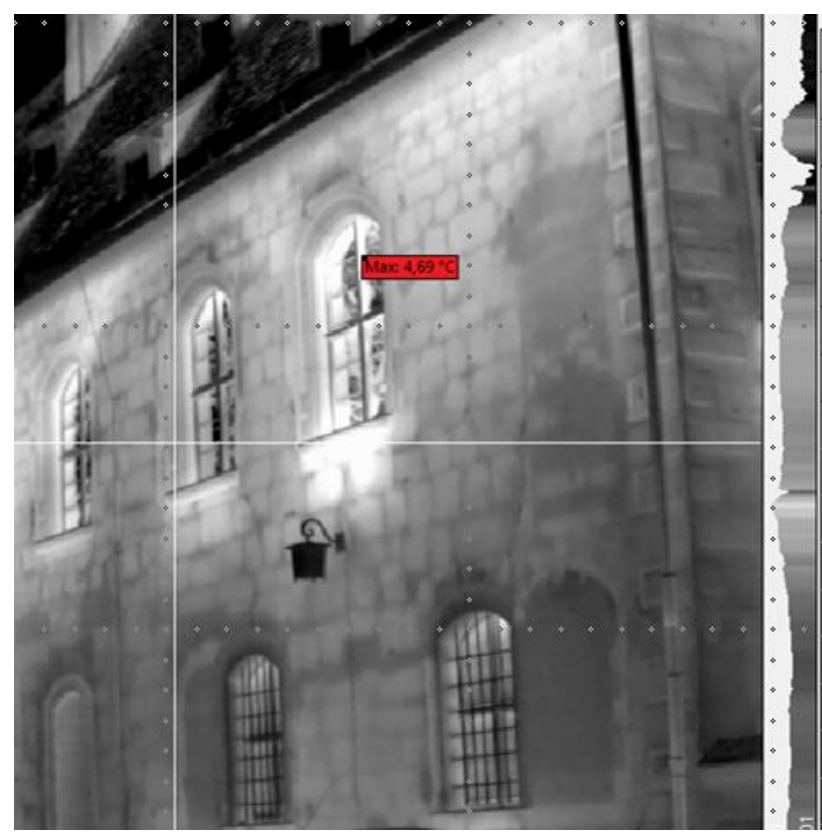

Figure 4: Greyscale visualisation of subsequently walled up openings under plaster.

The same holds true for regions of material damage or decay. The area below the right window in R1 exemplifies a structural injury in the masonry. (Fig.1) Two funnel-shaped cracks can be seen running from the upper to lower window. In visible wavelengths, they would only be detectable if a very detailed mapping was conducted. In the case of cracks underneath plaster, IRT is capable of displaying the extent and distribution of both structural and material-related degeneration forms. The radiometric examination reveals distinct disruption of the heat transition on the edges of crack lines. This disruption makes the crack lines appear more prominent, thus enhancing the recording of damages for Building Archaeological assessments. From that depiction, even conclusions regarding structural forces exceeding the fabric's potential are verifiable. The same holds true for water ingress, salinization and abrasion, all of which result in local thermal anomalies.

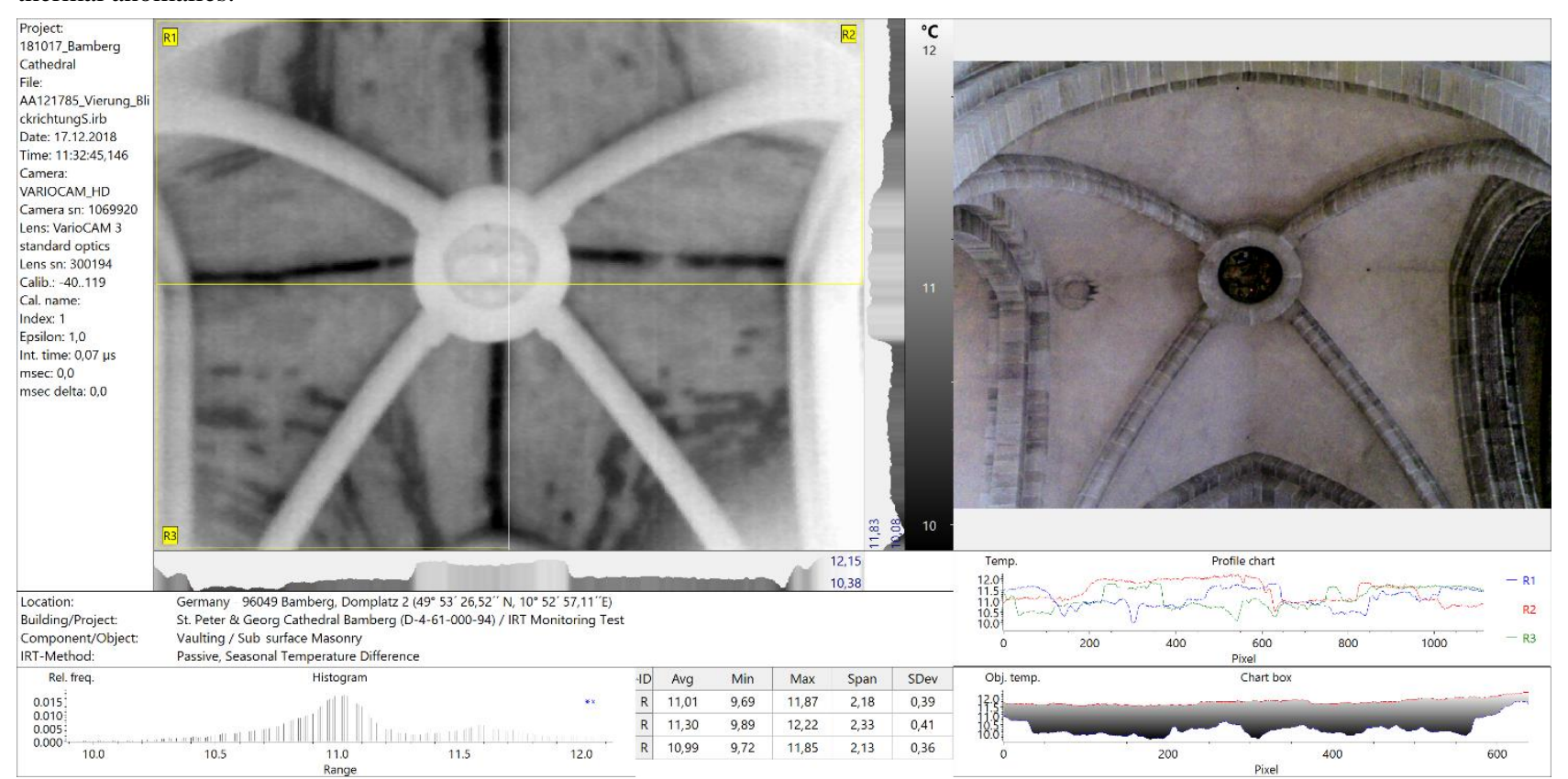

Figure 5: Greyscale visualisation and radiometric measurements of the vaulting structure over crossing of transept and aisle, depicting masonry

Figure 5: Greyscale visualisation and radiometric measurements of the vaulting structure over crossing
construction, variations in fabric, stone sizes and pattern.
3.2 Vaulted Masonry Structures

In addition to the vertically structured masonry walls, the IRT examination presented also applies to vaulted ceiling structures as horizontally oriented masonry. Masonry vaultings fall regularly under the scope of Building Archaeological examinations. As they are seldom reachable without scaffolding, contactless IRT-investigation over varying distances provides a useful measuring tool. The vaults in this case study belong to the centre aisle, side aisles, crossing and transept of Bamberg Cathedral. Their IRT documentation was executed from floor level with measuring distances between 10 and 25 meters, depending on the height of the individual vault.

The vaulting structure over the crossing of transept and aisle corresponds to that of a cross-ribbed vault with pointed arches, bounded by similar transverse ribs on all four sides. (Fig. 5) The diagonal ribs cross in a circularly edged oculus. Both longitudinal and lateral ridge lines finish at the oculus as well. While the vaulting webs are plastered and painted, the oculus, diagonal and transverse ribs remain untreated. Their radiometric examination clearly depicts varying masonry and mortar joint features. The ridge lines show significant alterations in stone size and fabric and the thermal emission of those stone lines clearly differentiates them from the enclosing vault severy stones, hinting at different thermal properties and therefore stone material.

Variations in heat capacity directly correlate to stone fabric in this case. Displaying a very distinct thermal behaviour, the masonry elements used must belong to different stone types.

Deductions from this information enables further Building Archaeological conclusions: As their positioning corresponds closely to the vaulting's ridge line, they apparently correspond to a superordinate constructive purpose. Further evidence visible in the thermogram is the larger size of those ridge line stones and their continuous and regular positioning. This is possibly due to the historic construction process. The ridge line stones could have been part of a stabilising sub-structure for the web's vaulting process. Additional investigations on their material properties could provide more detailed information on their structural relevance. Furthermore, the changing stone fabric towards the vault's gussets is noticeable. Following down the cross-ribs, each 
of the four gussets appears significantly darker and therefore colder or thermally inert regions in the thermogram.

These regions encompass the size of single stones or the masonry bonds of several stones with radiometrically detectable joint runs. Such distinct thermal capacity clearly hints at alterations in stone material. In contrast to the stone bonds in the ridge line, those thermally prominent in the gussets do not display a coherent distribution or thermal bond. Comparing each gusset, their number, position and allocation varies from gusset to gusset. However, all the stone alterations only reach halfway up the rib line towards the oculus. This might be a result of both the vaulting's construction process and the stones' constructive purpose as possible bracing elements of the gussets. All things considered, the configuration of masonry and joints visualised in the thermogram allows differentiated conclusions on the vaulting process.

Deducing from their irregular distribution, a later insertion of those stones, for example due to repair works, seems unlikely. Their consistent sizes also correspond to the surrounding masonry. In this case, further evidence from supplementary Building Archaeological examinations is needed to verify the theories mentioned above. IRT alone has outlined the findings, but the multicausal deductions require further detailed diagnostic methods, and an in-situ assessment of the vaulting structure. Similar findings can be detected in the side aisle vaults. They also consist of cross-ribbed vaultings with pointed arches, bounded by similar transverse ribs on all four sides. The pointed arches are lower than in the crossing, resulting in flat webs and moderate ridge lines.

The vault in the second bay displays comparable radiometric features. (Fig.6) Several vaulting web stones appear significantly darker in the thermograms, they have a lower temperature and are therefore thermally more inert. These occur mainly in the western and southern web, with a few also in the northern part of the vault. The eastern web does not show any radiometric anomalies. The amount, distribution and configuration of the more inert masonry variations differ from web to web. Even stone size varies.

In contrast to the crossing vault's thermal image, which enables clear conclusions on construction connections, the thermogram of the side aisle vaulting, whilst of the same radiometric quality and precision, is in this case only suitable as a basis the discussion of Building Archaeological construction possibilities. Supplementary examinations of the vault are required to support theories on the vaulting's construction, possible replacements and repair works. The vaulting configuration's irregularity in fabric speaks against a constructive coherency or a specific structural purpose. Explanations for the stone variation must therefore be supplemented with research on material parameters

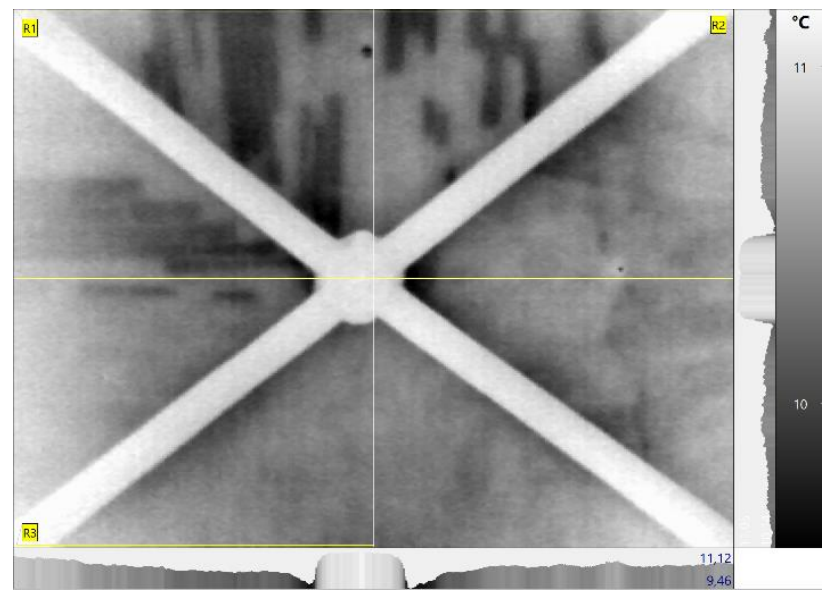

Figure 6: Thermogram of the plastered masonry vault in bay two. depicting joint structure, stone dimensions and variety of material characteristics. and subsequent restoration measures. A comparative study might clarify these records. In order to compare thermal anomalies, all of the bay vaults both in nave and side aisles were examined. The side aisle vaults in particular showed the previously described heterogenous layout of masonry components. Among the radiometrically tested constructions in the south aisle, one vault appeared completely different.

The thermogram of the eighth bay shows the highest amount of the thermally more inert stone fabric variety. (Fig.7) Apart from the lower part of the gussets, almost every part of the web consists of the radiometrically inert stone type, which appears darker in the thermal image. These vaulting stones are of smaller size and denser masonry bonds than the thermally comparable examples in the other vaults. While they evince a homogenous masonry configuration over the four webs, the stone variations in the gussets display irregular forms and layout in every web.

As these are singular records, it seems unlikely that this vaulting structure belongs to the original vaultings. There is no apparent constructive reason that justifies bay eight consisting of a completely different vault fabric. Although they are almost identical in size and height, neither bays one to seven in the southern side aisle nor the bays in the northern side aisle have any comparable features. This suggests that the differences in bay eight must be the result of changes due to a later restoration processes. The unusual stone alterations are further detectable in the ridgelines: All four of them consist of one row of alternating stone types with slightly larger dimensions than the enclosing web masonry. Those findings are comparable to the crossing vault's ridgelines. Thermal imaging can therefore be a suitable framework for investigating radiometric similarities and differences of comparable building structures.

The thermogram of the southern transept's vaulting displays another variation in the masonry structure. (Fig.8) Their configuration corresponds to a rectangular layout half the size of the crossings square, vaulted with cross-ribs. Due to their narrower proportions, the pointed arches are higher, and their ridgelines more distinctly built.

The masonry bonds differ from web to web. All of them appear to be quite heterogeneous with large parts of the thermally more inert stone type and irregularly positioned stone variations that appear brighter and therefore less inert in the thermograms.

Compared to vaults examined previously, the transept vaultings display a broad variation of stone sizes. The more inert stone type mainly comprises smaller forms with A few larger components running along individual joint lines. The larger, less inert stone types sometimes form rows, predominantly next to the gussets and ridgeline. In this case, superordinate constructive purposes could be the reason for their layout.

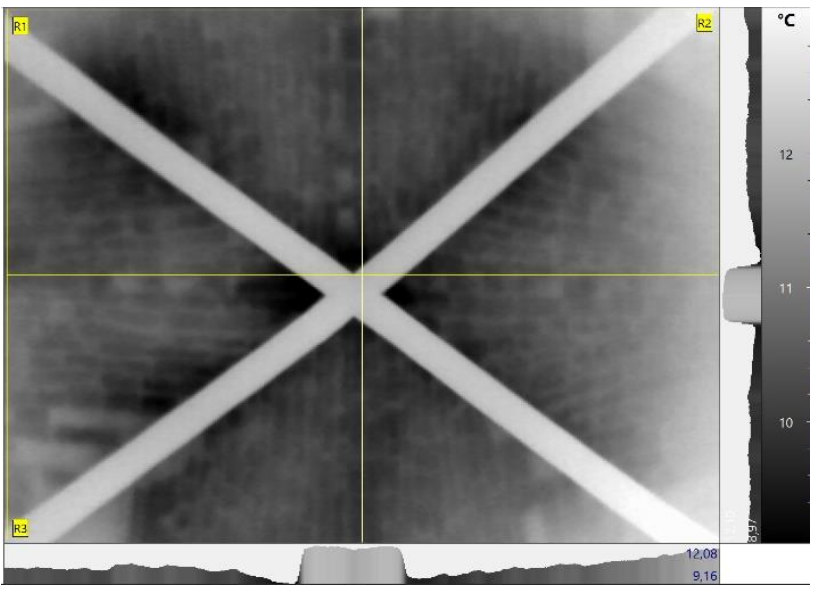

Figure 7: Thermogram of bay eight with the highest amount of thermally more inert stone fabric variety. 


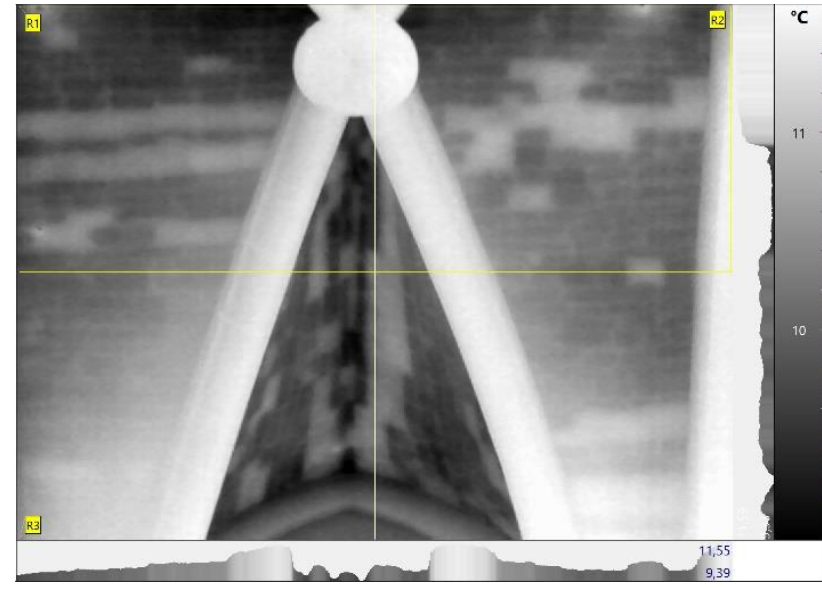

Figure 8: Thermogram of the southern transept's vaulting with heterogenous masonry pattern.

But they also appear as single vaulting components, especially in the narrower webs in the east and west. Their layout does not reveal any distinct pattern.

Both a random variation in vaulting fabric due to material availability or later exchanges and repair works could be possible explanations. However, while IRT provides the initial radiometric examination that generates a standardized mapping of material features, constructive configurations and thermal anomalies, any building archaeological theory needs additional examinations of joint lines, material analyses and comparative studies of vaulting techniques. IRT provides the initial radiometric examination that generates a standardized mapping of material features, constructive configurations and thermal anomalies.

Thus, IRT becomes even more important for Building Archaeological research as the vaultings' extradoses are rather difficult to examine properly: Most parts of the extradoses only show a coverage with plaster mortar and irregular stone sizes. With the intrados covered with paint layers and the extrados irregularly plastered, IRT remains an outstanding technique, to non-destructively reveal the vaultings features.

\section{DISCUSSION}

IRT as both a non-contact and non-destructive testing method proves highly useful for Building Archaeological research on masonry structures. On one hand, it enables contactless, yet precise radiometric documentation of very delicate or endangered cultural heritage objects such as fragile plasters and surfaces, deteriorating stone fabric or stressed vaulting constructions, with no material or surface alterations or modifications due to the IRT measuring process. On the other hand, IRT facilitates the examination of inaccessible or out of reach objects, such as the higher parts of facades or the intrados of vaults, without the need for scaffolding. Furthermore, long distance explorations are possible, depending on the thermal image's resolution. IRT therefore becomes an increasingly convenient non-intrusive investigation and visualisation device for out of reach building components. Especially in the context of preliminary examinations of unknown cultural heritage objects, IRT can provide fundamental information both on the masonry's general condition and to identify features which can then be examined in further detail. In the case of the plaster covered masonries examined in this research, IRT proved an effective tool, enabling quick overviews of complex or unfamiliar measuring settings. It is therefore a reliable tool for the acquisition of initial information about unknown historic fabric. The infrared camera clearly displays various structures under plaster: Stone types such as natural stones or bricks can be identified due to their thermal capacities, dimensions, layout and masonry bonds. Changes in masonry pattern are particularly detectable, enabling conclusions on construction processes and constructive features of individual structural building elements. The same holds true for displaying masonry's interstitial mortar joints, their width and joint run and even the alteration of their composition, if these result in varying thermal capacities.

It is, however, not possible to detect different stone surface processing techniques under plaster. IRT measurements at distance are not precise enough to differentiate surface reliefs on natural stone elements under plaster.

Besides conclusions regarding the original construction process, IRT also provides information for stratigraphic analysis. As later alterations of building components differ in fabric and material composition, they result indifferent radiometric reactions.

Therefore, repair works, replacements, stone, mortar and plaster alterations or exchanges of fabric are thermally detectable. The thermal differentiation of subsurface structures operates so well that even smaller anomalies and alterations are visualised in the thermal image, enabling conclusions about individual natural stone or brickwork parts, mortar and plaster patches and substitutes, their individual dimensions and distribution. IRT thus allows the differentiation of subsequent building phases through the visualisation of their different records and facilitates the detection of a cultural heritage object's construction history.

Deducing from the specific surface temperature of building fabric, its heat storage capacity and thermal conductivity, predictions of consistency, composition and structure of the stratigraphic layers substantiate theories on the chronology of building phases.

Similarly, structural and material-related damages such as cracks, water ingress, salinization and loss of density in masonry constructions are also detectable via IRT as their thermal performance reacts to material modifications and incoherencies. The implementation of IRT for damage evaluation is useful for restoration scientific research. For Building Archaeological examinations, IR reactive damages are particularly important if they result in stratigraphically relevant information.

However, thermograms complementarily also visualise the historic fabric's potential, the quality of the subsurface structures, their homogeneity or their intact frictional connection. A homogenous distribution of heat, comparable thermal conductivity behaviour and heat capacities identify intact masonry components. The assessment of such technical parameters supplements comprehensive Building Archaeological investigations, as it provides additional information on the current state of specific building components, enabling conclusions on structural and material alteration history and its further development. Moreover, these thermally visualisable parameters also outline a historic structure's overall quality. Not only do they illustrate damages and the history of decay, but at the same time qualify the durability and persistence of historic constructions. Taking into consideration the surrounding conditions makes IRT a reproducible method for generating and visualising radiometric data. Requirements for monitoring are feasible, as well as sequence recordings, enabling the documentation of thermal features changing over time. In the case of the plaster covered masonries examined, single thermal images were sufficient to document Building Archaeological features. As masonry constructions entail large heat capacities, thermal fluctuation remains slow. Compared to the IR camera's response time, masonries and vaultings are extremely stable thermal systems.

Since some of the masonry structures such as exterior walls are subject to changing weather situations, environmental conditions 
must be taken into consideration, and constitute relevant variables affecting the thermographic evaluation's quality. The thermal reaction of exterior walls is strongly dependant on the temperature difference between interior and exterior. Thermal behaviour therefore changes over the course of the year and even a single day. The maximum temperature difference occurs, of course, on cold winter days. With the outside temperatures remaining very low and the building interior heated, IRT utilises the maximum heat flux between inside and outside of the masonry wall. The same holds true for vaults under cold roof spaces. The passive thermographic method of the Building Archaeological investigations presented here makes use of this heat flux by detecting its individual intensity, which is dependent on the different building materials' heat capacities. Since the VarioCam IR camera measures temperature resolutions of up to $0.02 \mathrm{~K}$, cultural heritage objects surveys are not dependant on winter weather. As proven by the repeated examination of the masonry façade, proper radiometric recordings are feasible all year long. Particularly helpful is the temperature increase on exterior walls as the result of direct sunlight. In this case, it is not the heat flux through the building that is detected with IRT, but the heating behaviour of the surface and below-surface building fabric. Owing to differing heat capacities, the different materials heat up at various rates and to varying degrees, which is again radiometrically detectable. Consequently, the effect of sunlight over the course of a day must be considered when preparing IRT investigations. Drop shadow effects must be avoided, as they cause diffusive thermal reactions on building surfaces and can thereby mask relevant findings. Façade examinations should optimally be conducted on multiple days and with varying weather conditions, in order to ensure objective results.

Although not directly exposed to changing weather, interior building structures are also subjected to environmental conditions. Roof spaces over vaults can heat up significantly in the summer or cool down in winter, thus creating distinct temperature conditions on the vaultings extrados and influencing the radiometric state of the intrados. This also applies to the inner side of masonry walls. In this context, IRT also proved a useful method for monitoring the varying reactions of historic fabric to changing environmental conditions. From their changing thermal reactions, the comparison of different radiometric measurements for one masonry component can generate additional information and deductions on stratigraphic parameters.

Moreover, the portable IR camera proves a very time-efficient tool. It displays the measured data instantaneously, allowing for immediate in-situ analysis and interpretation, and for initial results to be checked and measurement settings adjusted accordingly. The speed of the examination processes, the camera's quick response and acquisition time enables the analysis of large building structures or a multitude of records even in brief campaigns.

It was therefore possible to conduct an in-depth examination of large masonry façade parts. whole building complexes or a greater number of single vaults in aisle, transept and nave under approximately stationary environmental conditions. Furthermore, the documentation of all vaults in one campaign allowed an instant comparison and consequently an initial categorisation according to presumed construction theories and related building sequences. Altogether, IRT proved a very useful method for the integration of Building Archaeological explorations with their respective radiometric records into stratigraphic analyses of cultural heritage objects.

\section{CONCLUSION}

The survey presented operated as a qualitative thermographic analysis, focusing on the examination of thermal patterns and anomalies. The comparison not of actual radiometric values or quantified temperature measurements - as in quantitative IRT but instead the overall thermal pattern of a measurement constitutes the core recording. Qualitative IRT provides perfect evidence of Building Archaeological phenomena by depicting relative temperature relations, junctions, discontinuities and disruptions.

The investigations demonstrate the benefits of IRT in both comparative studies and in-depth examinations of single objects, from singular construction items to large building structures. Thermal Imaging greatly facilitates the extensive examination of cultural heritage objects and is thus entirely recommendable as a standard non-destructive measuring method. The ability to detect and simultaneously display hitherto unknown subsurface structures and constructive interrelations demonstrates the huge potential of IRT as a preliminary assessment tool in Building Archaeology. Qualitative thermal imaging proved an applicable method for identifying contiguities. It enhances the contextualisation of both the individual object and its constructive coherencies and is above all applicable for a broad variety of thermo-structural assessments.

Furthermore, being able to adjust comparative measuring conditions even for on-site campaigns also makes IRT a promising monitoring method for endangered or deteriorating heritage fabric. IRT provides the initial radiometric examination that generates a standardised mapping of material features, structural configurations and thermal anomalies, thus enabling more detailed estimations of both their condition and constructive contiguity in a comprehensive assessment.

Employing infrared thermal imaging within the portfolio of remote sensing devices will enhance research methodology not only in the field of Building Archaeology, but also in every related scientific discipline dealing with cultural heritage objects at any scale. The added value of such a concise, probative measuring device lies in its broad applicability, its instantaneous visualisation of in-situ measurements and furthermore on its vast combinatorial potential with other pertinent methods such as 3Ddocumentation, SfM, deviation mapping, photogrammetric visualisations e.g.

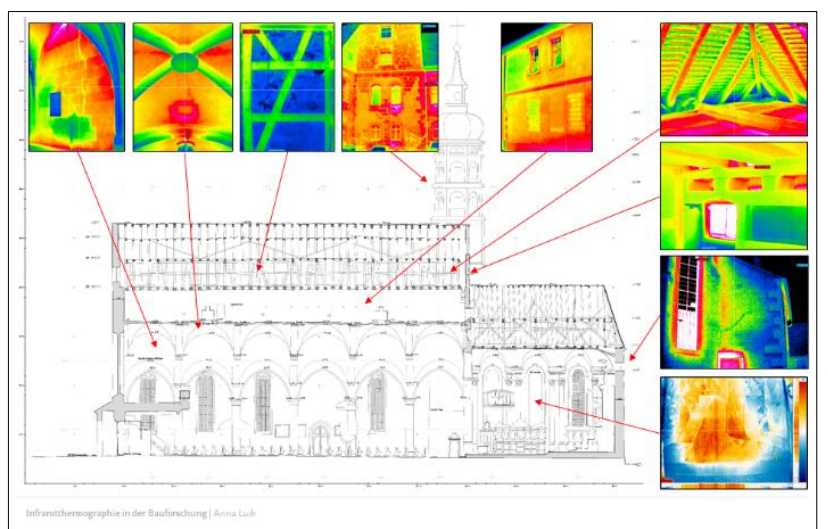

Figure 9: Potential applications of IRT for Building Archaeological investigations. 


\section{ACKNOWLEDGEMENTS}

The research project presented was conducted at the Centre for Heritage Conservation Studies and Technologies (KDWT), Department of Building History, Building Conservation and Building Archaeology, University of Bamberg, Germany. It is part of a series of studies on the applicability of IRT for Building Archaeology.

\section{REFERENCES}

Avdan, U., Kaplan, O., Kaplan, G., 2018: Determination of Building Materials with IR-Thermography in Historical Buildings. In: International Journal of Engineering and Geosciences, Vol. 3(2), pp. 56-60, DOI: 10.26833/ijeg.380752.

Bauer, E., Milhomem, P., Aidar, L., 2018: Evaluating the damage degree of cracking in facades using infrared thermography. In: Journal of Civil Structural Health Monitoring, Vol. 8(3), pp. 517-528, DOI: 10.1007/s13349-018-0289-0.

Bison, P., Bortolin, A., Cadelano, G., Ferrarini, G., Furlan, K., Grinzato, E., 2012: Geometrical correction and photogrammetric approach in thermographic inspection of buildings. In: QIRT 2012 - 11th Quantitative InfraRed Thermography Conference, 11-14 June, Naples, Italy. DOI: 10.21611/qirt.2012.285

Bodnar, J., Vrabie, V., Perrin, E., Mouhoubi, K., Detalle, V., 2012: Defect detection in mural painting by random infrared thermography associated with singular value decomposition and higher orders statistics. In: QIRT $2012-11^{\text {th }}$ Quantitative InfraRed Thermography Conference, 11-14 June, Naples, Italy. DOI: 10.21611/qirt.2012.154

Candoré, J., Bodnar, J., Detalle, V., Grossel, P., 2012: Nondestructive testing of works of art by stimulated infrared thermography. In: European Physical Journal: Applied Physics, EDP Sciences, 57(2), S. 21002.

Casapulla, C., Maione, A., Argiento, L., 2018: Infrared Thermography for the Characterization of Painted Vaults of Historic Masonry Buildings. In: International Journal of Structural Glass and Advanced Materials Research, 2(1), pp. 4654. DOI: $10.3844 /$ sgamrsp.2018.46.54.

Crova, C., Miraglia, F., 2018: Use and Efficacy of Thermography for Stratigraphic Analysis of Historical Buildings. In: Conservation Science in Cultural Heritage [S.1.], v. 18, p. 135146, DOI: doi.org/10.6092/issn.1973-9494/9231.

Fais, S., Casula, G., Cuccuru, F., Ligas, P., 2018: An innovative methodology for the non-destructive diagnosis of architectural elements of ancient historical buildings. In: Scientific Reports, 8(1), pp. 4334. DOI: 10.1038/s41598-018-22601-5.

Garrido, I., Lagüela, S., Arias, P., 2018: Autonomous thermography: Towards the automatic detection and classification of building pathologies. In: QIRT $2018-14^{\text {th }}$ Quantitative InfraRed Thermography Conference, 25-29 June 2018, Berlin, Germany. DOI:10.21611/qirt.2018.022

Glavaš, H., Hadzima-Nyarko, M., Buljan, I., Barić, T., 2019: Locating Hidden Elements in Walls of Cultural Heritage Buildings by Using Infrared Thermography. In: Buildings Buildings, 9(2), pp. 32. DOI: 10.3390/buildings9020032.
Kandemir-Yucel, A., Tavukçuoğlu, A., Caner-Saltik, E., 2007: In situ assessment of structural timber elements of a historic building by infrared thermography and ultrasonic velocity. In: Infrared Physics \& Technology, 49(3), pp. 243-248.

Kordatos, E., Exarchos, D., Stavrakos, C., Moropoulou, A., Matikas, T., 2013: Infrared thermographic inspection of murals and characterization of degradation in historic monuments. In: Construction and Building Materials, 48, pp. 1261-1265.

Largo, A., Angiuli, R., 2013: Thermographic Investigation of "leccese" Stone Masonry Structures. Nondestructive Testing of Materials and Structures. Springer Netherlands, Dordrecht, pp. 1137-1142.

Lerma, C., Mas, Á., Gil, E., Vercher, J., Torner, M., 2018: Quantitative Analysis Procedure for Building Materials in Historic Buildings by Applying Infrared Thermography. In: Russian Journal of Nondestructive Testing, 54(8), pp. 601-609. DOI: $10.1134 / \mathrm{S} 1061830918080065$.

Maierhofer, C., 2010: Monitoring - zuverlässige Quantifizierung und Bewertung von Schädigungsprozessen an Bauteiloberflächen und -grenzflächen. Stuttgart: FraunhoferIRB-Verlag (Forschungsinitiative ZukunftBau, F 2757).

Maierhofer, C., 2016: Erfassung und Bewertung von sicherheitsrelevanten Ablösungsprozessen bei Putzen und Fassadenelementen mit zerstörungsfreien Mess- und Prüfverfahren. ERBE. Abschlussbericht. Stuttgart: Fraunhofer IRB Verlag (Forschungsinitiative Zukunft Bau, F 2980).

Moropoulou, A., Avdelidis, N., Karoglou, M., Delegou, E., Alexakis, E., Keramidas, V., 2018: Multispectral Applications of Infrared Thermography in the Diagnosis and Protection of Built Cultural Heritage. In: Applied Sciences, 8(2), pp. 284. DOI: 10.3390/app8020284.

Ollig, R., Massimo V., 2009: Non-destructive investigation of historical plaster and stonework using thermography and radar survey exemplified at the facade of the cathedral of S. Giovanni dei Napoletani in Palermo, Italy In: Restauro, 115(4), pp. 252258 .

Rosina, E., 2012: Non-destructive investigations: A case study of a convent in Lombardy (Italy). In: Annales-Anali Za Istrske In Mediteranske Studije-Series Historia Et Sociologia, 22(2), pp. 539-554.

Rosina, E., Romoli, E., Pili, A., Suma, M., 2019: Lesson Learned On Monitoring Cultural Heritage At Risk Under Climate Changes: Strategy, Techniques And Results. In: The International Archives of the Photogrammetry, Remote Sensing and Spatial Information Sciences. XLII-2/W11, pp. 1017-1024. DOI: 10.5194/isprs-archives-XLII-2-W11-1017-2019.

Sfarra, S., Yao, Y., Zhang, H., Perilli, S., Scozzafava, M., Avdelidis, N. P., Maldague, X., 2019: Precious walls built in indoor environments inspected numerically and experimentally within long-wave infrared (LWIR) and radio regions. In: Journal of Thermal Analysis and Calorimetry, 129(2), pp. 29. DOI: 10.1007/s10973-019-08005-1.

Yastikli, N., Guler, E., 2013: Performance evaluation of thermographic cameras for photogrammetric documentation of historical buildings. In: Boletim de Ciências Geodésicas, 19(4), pp. 711-728. 